\title{
A EDUCAÇÃO POPULAR LATINO-AMERICANA COMO UM NOVO SENTIDO PARA A EDUCAÇÃO SOCIAL - PEDAGOGIA SOCIAL ${ }^{1}$
}

\author{
ÉRICO RIBAS MACHADO \\ Universidade Estadual de Ponta Grossa \\ (UEPG), Ponta Grossa, Paraná, Brasil
}

\begin{abstract}
Resumo: Este trabalho apresenta as análises de parte de reflexões teóricas para fundamentação da pesquisa de doutorado que teve como objetivo investigar o processo de internacionalização e de consolidação da Pedagogia Social como área de conhecimento das Ciências da Educação na Espanha e o processo, mais recente, de constituição da Pedagogia Social no Brasil. Neste texto é apresentada uma reflexão teórica a respeito do desenvolvimento de uma teoria pedagógica peculiar da América Latina. Tendo como base a perspectiva da Educação Popular, existe a defesa que esta pode sugerir fundamentos e inspirar novos caminhos para a estruturação de uma área que tem suas origens na Alemanha e, depois, Espanha, ou seja, do contexto europeu.
\end{abstract}

Palavras-chave: Educação Popular. Educação Social. Pedagogia Social. América Latina.

\section{INTRODUÇÃO}

Não se nega que os povos apresentem hoje, por tudo isso, caracteres comuns de vida, alimentando, embora, valores particulares, resultantes de formas peculiares de cultura. Compreendê-las e compará-las será atividade útil à visão de uma pedagogia de princípios universais. A identificação de uns e outros sistemas nacionais de ensino, em ensaios de tipologia, constitui o recurso preliminar para compreensão das formas possíveis dessas instituições e descoberta dos diversos fatores que nelas vêm a influir (LOURENÇO FILHO, 1961, p. 15). 
O movimento e os processos identificados e descritos na pesquisa evidenciam a preocupação cada vez mais crescente de entender a gênese da Educação Social - Pedagogia Social ${ }^{2}$ e suas variações pelo mundo afora. A escolha de Brasil e Espanha como cenários a serem investigados se justifica pelas áreas de influência que passaram a constituir: a Espanha difundindo sua perspectiva nos países de língua espanhola e portuguesa, e o Brasil ressignificando sua vasta experiência em diferentes práticas culturais e educativas. Este é o cenário a partir do qual emergem as questões que nortearam a pesquisa, a seleção da bibliografia e as metodologias escolhidas.

O contexto do pós-guerra tem sido apresentado na literatura especializada como o processo de ruptura política, social e econômica que justificou a emergência da Educação Social - Pedagogia Social na Alemanha e França (NATORP, 1913; NOHL, 1935; MOLLENHAUER, 1959; HÄMÄLÄINEN, 2003), mas quais as transformações sociais que a justificam na Espanha e no Brasil?

Esse questionamento inspirou como objetivo geral da tese investigar o processo de internacionalização da Pedagogia Social e suas repercussões no contexto espanhol e brasileiro, e como objetivos específicos: 1 . Identificar o processo de internacionalização da Pedagogia Social; 2. Verificar a concepção de Pedagogia Social na formação dos Educadores Sociais na Espanha; e 3. Identificar a concepção de Pedagogia Social em construção no Brasil.

Para que fossem alcançados os objetivos propostos, a metodologia foi organizada de maneira a dar conta dos diferentes processos de coleta e análise de dados que foram necessários para a sua estruturação, tendo como perspectiva de fundo a abordagem comparativa, recorrendo-se, em cada capítulo, a procedimentos metodológicos diferenciados. Desta maneira, o estudo foi organizado a partir da proposta de "triangulação de perspectivas", explicado por Flick (2009, p. 361), como a"combinação de diversos métodos, grupos de estudo, ambientes locais e temporais e perspectivas teóricas distintas para tratar um fenômeno", especificamente o tipo descrito por Denzin (1989 apud FLICK, 2009, p. 361), chamado triangulação metodológica. Fielding e Schereier (2001, p. 31) esclarecem que essa perspectiva pode ser organizada a partir de duas abordagens: o sequenciamento e o hibridismo. Para a tese utilizou-se da abordagem do sequenciamento, que significa que os métodos quantitativos e qualitativos são combinados dentro da análise de uma mesma fase dos estudos.

A proposta metodológica para a pesquisa permitiu estabelecer relações históricas e contextuais que foram mais amplas e que resultaram no estabelecimento descritivo e analítico de como teorias pedagógicas e 
práticas educativas estabelecem rumos para a educação de determinados povos e culturas.

A discussão que segue nesse trabalho é o resultado da reflexão a partir de publicações sobre a temática, estabelecendo possíveis elementos comparativos em processo inicial de desenvolvimento que permitem acessar quais os elementos que podem aproximar a Educação Social - Pedagogia Social da Educação Popular, no contexto latino-americano, e os reflexos dessa aproximação em uma possível formação e profissionalização do Educador Social.

INSPIRAÇÕES DA EDUCAÇÃO POPULAR LATINO-AMERICANA PARA UMA NOVA EDUCAÇÃO SOCIAL - PEDAGOGIA SOCIAL

É a crença de que podemos ser, enquanto povo, muito mais do que somos; de que não estamos condenados ao destino da linhagem de Aureliano Buendía de viver tragicamente presos a um eterno presente. Como os personagens de Gabriel García Marques, encurralados no seu mundo e sem perspectivas de uma segunda oportunidade sobre a face da terra (STRECK, 2005, p. 55).

As afirmações construídas no corpo do texto foram desenvolvidas considerando a importância dos estudos científicos que buscam, a partir de análises antropológicas, identificar os processos culturais e filosóficos próprios do continente latino-americano e que resultam em práticas pedagógicas e relações educativas específicas de povos que não estão no centro do mundo, mas que produziram e estabeleceram lógicas peculiares de existência e de pensamento sobre essa existência.

Por meio dos estudos, foi identificada a existência das vertentes alemã, francófona e anglo-saxã da Pedagogia Social e suas influências sobre diversos países, mas desenha-se uma vertente latino-americana que se inspira na tradição da Educação Popular, especialmente a linha teórica inspirada em Paulo Freire. Foi possível concluir na pesquisa realizada que o Brasil aparece no contexto internacional da Pedagogia Social com devida relevância, para além de uma relação de mera importação de matrizes estrangeiras ou de adaptação de conhecimentos externos, assumindo um papel importante no processo de amadurecimento da área, bem como na renovação do movimento internacional da Pedagogia Social, a partir de seu acúmulo de experiências na Educação Popular, reflexo também de um contexto latino-americano. 
Conforme Schriewer (1995, p. 270), como reação à dominação global angloamericana na área da pesquisa e da disseminação científica, o debate tem focalizado recentemente as tendências conflitantes da internacionalização versus indigenização das Ciências Sociais, bem como o desenvolvimento das "sociologias indígenas específicas" a diferentes culturas em oposição à Ciência Social Universal.

O texto de Rouquié (1991) esclarece o quanto é complexo pensar e analisar a América Latina. Em seus argumentos, ele demonstra fatores históricos, culturais, linguísticos, climáticos, geográficos, econômicos etc., que mostram a enorme diferença existente entre nações próximas. Como o próprio afirma:

Se a existência de uma América Latina é problemática, se a diversidade das sociedades e das economias se impõe, se a delimitação das diferentes nações é um dado básico de seu funcionamento, não deixa de ser verdade que uma relativa unidade de destino, mais sofrida que escolhida, aproxima as repúblicas irmãs. Ela é legível nas grandes fases da história, perceptível na identidade dos problemas e das situações que enfrentam atualmente essas nações. (ROUQUIÉ, 1991, p. 26)

A busca pelo entendimento de qual seria a principal característica do pensamento pedagógico latino-americano, bem como localizar sua origem, não é uma tarefa simples, talvez no contexto histórico atual irrealizável, mas a busca por certos esclarecimentos se faz necessário, compreendendo que esse processo é um fator importante para a demarcação da identidade de um povo, cuja característica principal é - talvez - a sua diversidade de características.

O pensamento de Gabriel García Márquez - indicado por Streck (2005), - talvez ajude a definir a linha de reflexão necessária para a construção do conhecimento pretendido. Conceber a Educação como "órgão mestre" da mudança social é entender que, por meio dela, seja possível superar aspectos opressores. Entender que a Educação faz parte de toda a vida de um sujeito é romper com suas concepções conservadoras. Compreender que a Educação pode inspirar "um novo modo de pensar" para "descobrir quem somos" é concebê-la como conscientizadora. E, finalmente, atrelar a Educação a "uma sociedade que se queira mais a si mesma" é defender um futuro mais justo para os sujeitos do mundo.

Pensar a pedagogia latino-americana a partir da reflexão acima já pode indicar uma tendência em defini-la com duas características principais: transformadora e conscientizadora. Mesmo acreditando que essa é a melhor 
concepção, será que essa pedagogia que se pretende conhecer, pode ser caracterizada dessa maneira?

A diferença entre o ideal de uma concepção e a sua prática real é o que deve ser considerado, e como será descrito nos argumentos a seguir, não se pode afirmar que a pedagogia latino-americana é isto ou aquilo, mas relativizar, considerando que ela pode acontecer em um determinado momento histórico ou contexto social, desta ou daquela maneira, por isso a complexidade em analisá-la. A inspiração esperançosa a partir da citação corrobora com a afirmação de Streck, Adams e Moretti (2010, p. 20), de que as reflexões devem buscar o entendimento de que:

Por ser herdeira de uma determinada formação histórica e cultural, forjou-se nesta parte do mundo um pensamento com algumas características próprias, em princípio, nem melhor nem pior que o pensamento em outros lugares. Mas é um pensamento que, em meio à fugacidade de ideias de fora que, como ondas, se sucedem em modas, busca encontrar raízes por onde continua subindo a seiva que, mesmo imperceptível, continua alimentando práticas e esperanças.

Esse trecho induz à formulação de duas perguntas centrais que podem ser o fio condutor da busca pelas futuras respostas: Qual seria a raiz, ou as raízes, da pedagogia latino-americana? Quais os meios utilizados para a perpetuação, desenvolvimento e fortalecimento de uma concepção pedagógica latino-americana que se acredita existir?

Citando Alcira Argumedo, Streck (2005, p. 59) apresenta três períodos que podem expressar a existência de uma pedagogia antiga no continente em questão. $O$ primeiro período se refere ao das culturas pré-colombianas, que serve para exemplificar os argumentos anteriores. É um período em que existiam povos que viviam da caça e coleta até povos que possuíam um elevado nível de desenvolvimento científico, a exemplo dos maias, que criaram um calendário mais sofisticado que o do povo grego, como se destacava também a arquitetura da cidade de Tenochtitlán, que se igualava às"melhores cidades européias". Ainda como exemplo desse período:

Tanto entre os astecas quanto entre os incas havia um sistema educativo que dava sustentação ao seu desenvolvimento tecnológico. Entre os povos menos desenvolvidos do ponto de vista tecnológico as estratégias pedagógicas estavam embutidas nos seus elaborados rituais religiosos ou na riqueza dos mitos. Ou, então, como negar a competência da educação quando um menino consegue apresentar 661 nomes de plantas e 336 nomes de aves (STRECK, 2005, p. 59). 
Em outro texto, Streck, Adams e Moretti (2010, p. 21) organiza três eixos temáticos que servem como articuladores para entender essas discussões sobre o pensamento pedagógico da América Latina: $1^{\circ}$ - Colonialidade pedagógica: como superar o eurocentrismo?; $2^{\circ}$ - A luta pela educação: alguns atores e lugares; $3^{\circ}$ - A pedagogia latino-americana: desafios e tarefas.

O primeiro eixo corrobora o segundo período destacado por Alcira Argumedo:

O segundo período é o das conquistas, um período de devastação das culturas indígenas e africanas, com fortes e violentos conflitos. Segue-se o período do domínio colonial, entre os séculos XVII e XVIII, quando a resistência aberta tinha se tornado praticamente inviável. (apud STRECK, 2005, p. 59-60).

Explicando que colonialidade"em processo, atua como uma matriz subjacente do poder colonial que seguiu existindo depois da independência política", Streck, Adams e Moretti (2010, p. 21) defende que é preciso superar essa condição, rompendo com a assimilação direta, ou melhor, a imposição de ideais estrangeiros a realidades diversas. De acordo com os autores, essa condição coloca a cultura e o povo latino-americano como inferiores, rebaixados, não reconhecidos, sendo que toda a importância dos fatos históricos, como também da produção de conhecimentos, é dada aos europeus.

Fica clara esta afirmação com o exemplo dos autores em relação às antigas civilizações desse continente, como Asteca, Inca e Maia que, juntamente com suas crenças, línguas e formas de convívio, foram renegadas como culturas inferiores. Mas há o destaque de que, como afirmam Streck, Adams e Moretti (2010, p. 22), "sempre houve movimentos de resistência dos povos nativos que deram brecha para o surgimento de um pensamento fronteiriço". Em um movimento contraditório, mas concreto, Streck (2005, p. 58) esclarece que:

Os quinhentos anos da aportagem de Colombo (1492) e Cabral (1500) ao que hoje é a América e o Brasil serviram para colocar lado a lado, quando não em choque, as versões que cercam estes acontecimentos. Por um lado, festejos pela integração no mundo da civilização européia e, por outro, as denúncias pela usurpação das terras e pela destruição das culturas. Interessa-nos este segundo lado da história na esperança de resgatar alguns elos perdidos que ajudem na reconstrução de nossa memória pedagógica. O pressuposto é de que junto com o silenciamento das culturas foram silenciadas as suas pedagogias que continuaram sobrevivendo na clandestinidade. 
Talvez seja por meio dos movimentos de resistência, na contradição com o outro, que as identidades foram demarcadas, e esse pensamento fronteiriço perpetuado. Pensamento sem predominância, haja vista a força colonialista da busca pela modernização, principalmente, como afirmam os autores, por meio do "controle epistêmico, ou seja, o controle do conhecimento e da subjetividade" (STRECK, ADAMS, MORETTI, 2010, p. 23).

Continuando o relato, os autores contextualizam que o processo colonizador é cruel, e que com ele tudo o que existia antes deixa de ser considerado, é como se não existisse um povo com sua cultura, com seu jeito de ser e existir. O processo seguinte é a invasão, a imposição de ideais, em que os colonizados devem aprender a cultura dos colonizadores, tanto em questões materiais, que envolvem questões de trabalho e de sobrevivência, como também alçando para o nível subjetivo desse povo, inculcando obrigatoriamente crenças religiosas, ideológicas e verdades absolutas. Vale o exemplo do Brasil, no processo de colonização dos portugueses, em que os jesuítas eram os responsáveis por civilizar os brasileiros legítimos (índios), formando-os com os únicos conhecimentos de vida e religiosos válidos, passando por processo de negação total de culturas e crenças já existentes. Para Streck, Adams e Moretti (2010, p. 23):

Enfrentar a colonialidade pedagógica, num contexto epistemológico do sul, significa, portanto, aprender com o espírito que produziu culturas e conhecimentos, mas sem repetir e copiar servilmente os frutos de culturas do norte. Compreender-se aqui o sul (países do sul, ótica do sul) como metáfora do sofrimento humano causado pelo colonialismo capitalista. Trata-se do sul global (em oposição ao norte) criado pela expansão colonial da Europa que subjugou e expropriou o sul do planeta (América Latina, África, parte da Ásia)

Os autores explicam que um elemento a ser considerado para a compreensão dessa pedagogia é considerar a relação contraditória, mas real, entre as culturas europeia, indígena e africana, esclarecendo que a primeira é considerada como o projeto ideal de modernidade, e as outras duas, renegadas à colonialidade. Eles defendem que a postura adequada não é negar a importância da busca pela modernização dos povos, mas sempre entender esse processo com uma atitude crítica, em que a lógica da monocultura eurocêntrica deve ser questionada, abrindo caminhos para outros paradigmas, afinal:

A América Latina são [sic] os descendentes astecas, maias, incas, guaranis, mapuches, aimaras e tantos outros povos indígenas; são os descendentes dos europeus; são os descendentes dos escravos africanos. É cada um e são todos (STRECK; ADAMS; MORETTI., 2010, p. 23). 
Para entender a colonialidade, que tem como principal imposição as ideias e pensamentos, a filosofia ocupa papel central nas discussões, pois os autores explicam que o pensamento hegemônico difundido pelos colonizadores é pautado na filosofia clássica greco-romana. A filosofia "oficial", que é a considerada nos currículos universitários e escolares, é a que segue "princípios lógicos e hermenêuticos da ilustração europeia", e que não permite considerar tipos de conhecimentos diferenciados ou de outras origens. Serve como exemplo os estudos que estão sendo realizados na formulação de uma filosofia andina, que de acordo com Streck, Adams e Moretti (2010, p. 24) é originária de Abya Yala, que pode indicar os meios para se recuperar uma "sabedoria que foi oprimida e invisibilizada":

Os vetores orientadores dessa filosofia são determinados pela dialética de complementaridade desde arriba y abajo, da esquerda e direita, do vetor feminino e masculino. Enquanto a filosofia tradicional, de origem grega, se caracteriza pelas dicotomias entre interior-exterior, transcendente-imanente, eterno-passageiro, essencial-acidental, universal-particular e a dicotomia entre material-espiritual ou mundano-divino, a filosofia andina parte de outro princípio: a relacionalidade. Tudo é interdependente com tudo, numa rede de solidariedade cósmica onde cada ente é parte. Enquanto para Aristóteles, a relação seria um acidente, na filosofia andina ela se constitui no mito fundante. Desse princípio da relacionalidade derivam outros, como a complementaridade, a correspondência, a reciprocidade, a ciclicidade e a inclusividade. Conforme Estermann (2007, p. 49) "a filosofia andina pensa em dualidades polares e não em dualismos", o que aparece como uma chave interessante para elucidar projetos pedagógicos emancipadores afinados com nosso ser latino-americano (STRECK; ADAMS; MORETTI, 2010, p. 24).

Em relação ao segundo eixo - A luta pela educação: alguns atores e lugares, os autores contextualizam que é necessário o reconhecimento, "resgate e (re)construção do pensamento pedagógico latino-americano em personagens históricos que exerceram um papel profético, antecipando possibilidades emancipadoras" (STRECK; ADAMS; MORETTI, 2010, p. 25). As mulheres e os homens que são apresentados em seu texto buscaram de diferentes maneiras aprofundar "o diagnóstico da América Latina, a fim de conhecer as causas, para, a partir daí, indicar respectivos caminhos de solução". Aprofundando os estudos, é possível identificar um conjunto de ideias e ações que podem ser relacionadas e que podem traduzir ideários que formam a lógica de um pensamento pedagógico, justamente por le- 
varem a algo, proporem mudanças, saindo de um estado de opressão para conscientização, isso é educativo.

Esse eixo pode ser relacionado ao terceiro período apresentado por Alcira Argumedo, no texto de Streck (2005, p. 60):

Por fim, há o período dos processos político-culturais a partir da emancipação, com a integração de novos atores sociais e a crescente formação de uma intelectualidade identificada com as camadas subalternas. Esta periodização da formação de uma matriz da vertente popular do pensamento latino-americano possibilita identificar algumas estratégias pedagógicas as quais mais adiante servirão de suporte para a educação popular. Aqui elas são entendidas como pedagogias por formarem um conjunto de saberes e de práticas com relativa coerência interna própria.

É fundamental que exista o registro histórico dos nomes dos importantes pedagogos latino-americanos que são originários de determinados países, mas suas práticas geraram interpretações teóricas e pedagógicas, influenciaram e influenciam a educação em toda a América Latina, principalmente a Educação que não está propriamente estabelecida nas leis e políticas, mas sim as relações educativas que enaltecem princípios culturais e filosóficos de cada povo, expressando suas tradições e que deram origem ao que se conhece por Educação Popular e que por isso devem compor fundamentos latino-americanos que podem e estão propiciando novos trilhos para antigos caminhos da Pedagogia Social.

Já o terceiro eixo - A pedagogia latino-americana: desafios e tarefa - consiste na percepção dos autores quanto a complexidade de estudar a América Latina, devido, tanto a sua grandeza geográfica quanto a sua diversidade histórica e cultural. Streck, Adams e Moretti (2010, p. 29) apontam três tarefas principais como grandes desafios para educadores e pedagogos desse continente: a primeira se refere a "debruçar-se sobre esta realidade complexa e multifacetada e escutá-la"; a segunda tarefa "consiste em tomar plena consciência do tipo de inserção que coube a América Latina, em grande parte através da Educação, no processo de ocidentalização e modernização"; e a terceira é o"desenvolvimento de uma pedagogia da práxis, entendida esta como a ação transformadora das condições que se colocam como obstáculo para o desenvolvimento do ser mais (Paulo Freire) de todas as pessoas e de cada uma".

Com clareza destas contradições e complexidades, alguns pontos podem ser levantados para possíveis aprofundamentos. 
O primeiro aspecto é conhecer a cultura existente antes da colonização. Quais eram os costumes, o que se ensinava e o que se aprendia nos povos antigos? Existem estudos que indicam as possíveis respostas. Avançando no tempo, o segundo aspecto é verificar o que se somou à cultura do povo latino-americano, com as influências dos colonizadores? A possível análise deste aspecto pode ser verificada por meio da produção dos diferentes personagens importantes de toda a história do continente, principalmente suas lutas e reivindicações por uma sociedade mais justa.

Mas para que todo esse processo seja superado e que algo possa ser apreendido, é preciso considerar conhecimentos até então não considerados, ou esquecidos.

Mas que tipo de conhecimento deve ser reconsiderado?

As discussões acima parecem enaltecer um tipo de conhecimento válido e predominante, é o que Boaventura de Souza Santos e Menezes (2010) vão chamar de pensamento abissal, em que ele busca a reflexão de que existem os saberes válidos que ficam para cá de uma "linha" e os saberes que são renegados que ficam pra lá da "linha". Streck (2005, p. 64) vai analisar que:

[...] estamos diante de um quadro que requer uma teoria pedagógica plural, cuja articulação se dá a partir da inserção na matriz formulada pelas ausências e emergências, pelos saberes pedagógicos encobertos ou silenciados e pelas vozes que surgem como sobrevivência, resistências e como desejo de reinvenção das possibilidades de vida. A pedagogia de Paulo Freire é um bom exemplo de uma pedagogia formulada dentro de uma racionalidade cosmopolita, mas enraizada na realidade das classes populares. São propostos novos critérios para o que se entende por coerência e por rigorosidade, fugindo de trampas dualistas que exigem opções entre termos que não se excluem nem se contrapõem, como culturalismo e estruturalismo, entre biologia e história, entre outras.

Essas afirmações tornam-se críticas, envergando-se para o outro lado da vara, na defesa de quem, ou de um povo que simplesmente nunca foi reconhecido ou valorizado. E o mais interessante é que esse reconhecimento não seja a partir de uma cultura que os sempre dominadores vão achar válidas, mas de uma pedagogia construída a partir de uma cultura própria e que seja valorizada entre seus iguais. O destaque é que há indícios de que essa pedagogia está se constituindo através dos tempos justamente pelas lutas e a busca de uma identidade existente, latente, mas reprimida no povo latino-americano. 
Compreender a Pedagogia Social como teoria geral da Educação Social, permite entendê-la como a leitura teórica e científica de processos educativos derivados das relações culturais de diferentes povos. No contexto latino-americano, existem as práticas de Educação Popular que expressam essas relações culturais e educativas, e por isso alguns pesquisadores vêm destacando a relação possível entre as três perspectivas. No Quadro comparativo abaixo, elaborado por Rosa-Maria Torres, essas relações são expressas de maneira a indicar a relação existente entre as áreas:

QUADRO: COMPARAÇÃO ENTRE EDUCAÇÃO SOCIAL E EDUCAÇÃO POPULAR

\begin{tabular}{|c|c|c|}
\hline & $\begin{array}{l}\text { EDUCAÇÃO SOCIAL } \\
\text { (Europa/ Dinamarca) }\end{array}$ & $\begin{array}{l}\text { EDUCAÇÃO POPULAR } \\
\text { (América Latina) }\end{array}$ \\
\hline $\begin{array}{l}\text { CONTEXTO } \\
\text { HISTÓRICO }\end{array}$ & $\begin{array}{l}1940 \text { - após II Guerra Mundial. } \\
\text { AIEJI (Associação Internacional } \\
\text { de Educadores Sociais). Nome } \\
\text { original Association Internationale } \\
\text { des Éducateurs des Jeunes } \\
\text { Inadaptés - criada em } 1951 . \\
\text { "Da caridade, assistencialismo e } \\
\text { filantropia ao bem - estar social } \\
\text { como um direito humano". }\end{array}$ & $\begin{array}{l}1960 \text { - } 1970 \text { - após ditaduras e } \\
\text { governos militares da América Latina. } \\
\text { Brasil - trabalhos e ideias de Paulo Freire. } \\
\text { Libertação e Emancipação humana. } \\
\text { Igrejas e grupos religiosos envolvidos. }\end{array}$ \\
\hline $\begin{array}{l}\text { PÚBLICO - ALVO: } \\
\text { ORIGENS }\end{array}$ & $\begin{array}{l}\text { Crianças de rua e órfãs após } \\
\text { a II Guerra Mundial. }\end{array}$ & $\begin{array}{l}\text { Adultos analfabetos (em 1950, metade } \\
\text { da população local era analfabeta). }\end{array}$ \\
\hline $\begin{array}{l}\text { PÚBLICO - ALVO: } \\
\text { ATUALMENTE } \\
\text { (PERSPECTIVA } \\
\text { HISTÓRICA) }\end{array}$ & $\begin{array}{l}\text { Crianças } \\
\text { Adolescentes } \\
\text { Jovens } \\
\text { Adultos (incapacitados) } \\
\text { Terceira Idade }\end{array}$ & $\begin{array}{l}\text { Adultos } \\
\text { Jovens } \\
\text { Adolescentes } \\
\text { Crianças } \\
\text { Famílias } \\
\text { Comunidades } \\
\text { Movimentos Sociais }\end{array}$ \\
\hline $\begin{array}{l}\text { CARACTERÍSTICAS } \\
\text { DO PÚBLICO-ALVO }\end{array}$ & $\begin{array}{l}\text { Desajustado - pobreza } \\
\text { Perturbado } \\
\text { Incapacitado } \\
\text { Morador de rua } \\
\text { Marginalizado } \\
\text { Excluído } \\
\text { Em risco } \\
\text { Com necessidades especiais }\end{array}$ & $\begin{array}{l}\text { Pobreza } \\
\text { Marginalizado } \\
\text { Analfabeto } \\
\text { Semianalfabeto } \\
\text { Baixa escolaridade }\end{array}$ \\
\hline
\end{tabular}

(continua) 


\begin{tabular}{|c|c|c|}
\hline & $\begin{array}{l}\text { EDUCAÇÃO SOCIAL } \\
\text { (Europa/ Dinamarca) }\end{array}$ & $\begin{array}{l}\text { EDUCAÇÃO POPULAR } \\
\text { (América Latina) }\end{array}$ \\
\hline $\begin{array}{l}\text { CARACTERÍSTICAS } \\
\text { DOS EDUCADORES }\end{array}$ & $\begin{array}{l}\text { - Ênfase na profissionalização } \\
\text { e na formação continuada. } \\
\text { - Defesa da profissão e das } \\
\text { condições de trabalho. }\end{array}$ & $\begin{array}{l}\text { - Pequena atenção para a } \\
\text { profissionalização ou para } \\
\text { desenvolvimento de carreira. } \\
\text { - Diversas ofertas de oportunidades de } \\
\text { formação de maneira rápida - curta. } \\
\text { - Algumas universidades e ONGs } \\
\text { oferecem cursos universitários. } \\
\text { - Vários trabalhos desenvolvidos } \\
\text { em regime de voluntariado. }\end{array}$ \\
\hline $\begin{array}{l}\text { ORGANIZAÇÃO } \\
\text { DOS EDUCADORES }\end{array}$ & $\begin{array}{l}\text { - Organização de Associações } \\
\text { profissionais. } \\
\text { - Organizações nacionais, } \\
\text { europeias e internacionais. }\end{array}$ & $\begin{array}{l}\text { - Não existem organizações } \\
\text { profissionais, às vezes são } \\
\text { organizadas associações locais. } \\
\text { - Existem algumas organizações locais, } \\
\text { nacionais ou internacionais (ex: CEAAL } \\
\text { - Consejo de Educación de Adultos } \\
\text { de América Latina, ONG network). } \\
\text { - Movimentos sociais possuem } \\
\text { seus próprios programas } \\
\text { de Educação Popular. }\end{array}$ \\
\hline $\begin{array}{l}\text { OCUPAÇÕES } \\
\text { SIMILARES } \\
\text { IDENTIFICADAS }\end{array}$ & $\begin{array}{l}\text { Trabalhadores Sociais, Professores, } \\
\text { Enfermeiros, Psicólogos, Terapeutas. }\end{array}$ & $\begin{array}{l}\text { Professores, Trabalhadores Sociais, } \\
\text { Trabalhadores de Extensão, Agentes } \\
\text { Comunitários, Líderes Comunitários, } \\
\text { Animadores Culturais. }\end{array}$ \\
\hline $\begin{array}{l}\text { AMBIENTES DE } \\
\text { TRABALHO }\end{array}$ & \multicolumn{2}{|c|}{ Principalmente educação não-formal e ambientes não-escolares } \\
\hline $\begin{array}{l}\text { ÁREAS DE } \\
\text { TRABALHO }\end{array}$ & $\begin{array}{l}\text { Educação Especial } \\
\text { Mediação de Conflito } \\
\text { Animação Sociocultural } \\
\text { Educação de Adultos } \\
\text { Educação Escolar } \\
\text { Educação Ambiental } \\
\text { Educação e Lazer }\end{array}$ & Todas as áreas em potencial. \\
\hline FINALIDADES & $\begin{array}{l}\text { Adaptação } \\
\text { Participação } \\
\text { Cidadania } \\
\text { Mudança Social } \\
\text { Justiça Social }\end{array}$ & $\begin{array}{l}\text { Conscientização } \\
\text { Participação } \\
\text { Organização } \\
\text { Empoderamento } \\
\text { Mudança Social } \\
\text { Mudança Política } \\
\text { Justiça Social } \\
\text { Cultura dos direitos }\end{array}$ \\
\hline
\end{tabular}

(continua) 


\begin{tabular}{|l|l|l|}
\hline & $\begin{array}{l}\text { EDUCAÇÃO SOCIAL } \\
\text { (Europa/ Dinamarca) }\end{array}$ & $\begin{array}{l}\text { EDUCAÇÃO POPULAR } \\
\text { (América Latina) }\end{array}$ \\
\hline PRINCIPIOS & $\begin{array}{l}\text { Diálogo } \\
\text { Respeito } \\
\text { Participação } \\
\text { Vozes dos educandos }\end{array}$ & $\begin{array}{l}\text { Diálogo } \\
\text { Respeito } \\
\text { Participação } \\
\text { Vozes dos educandos }\end{array}$ \\
\hline $\begin{array}{l}\text { DIMENSÕES DO } \\
\text { TRABALHO }\end{array}$ & Pedagógico, social, político e ético \\
\hline
\end{tabular}

FONTE: Elaborado por Rosa-María Torres (Tradução nossa). Disponível em: < https://otra-educacion.blogspot.com.br/2011/10/social-education-view-from-south.html I>. Acesso em: 05 dez. 2016.

Ainda com o intuito de comprovar as possíveis relações entre a Pedagogia Social/Educação Social e Educação Popular, identificam-se outras pesquisas realizadas e publicações que abordam essa questão, principalmente no contexto brasileiro: Paiva (2009), Scocuglia (2009), Ryynänen (2009), Machado (2010; 2011; 2012), Moura, Souza Neto e Silva (2011), Streck e Santos (2011), Gadotti (2012).

Também foram identificadas outras publicações relevantes que apresentam o debate de como a Pedagogia Social está em processo nos seguintes países deste continente: No Uruguai com Jorge Camors, A Pedagogia Social na América Latina (2009), Lo social: un camino para recuperar identidades (2011) e El Educador Social en Uruguay (2012); Marcelo Morales, Hernán Espiga e Walter López, Educación Social en Uruguay: apuntes para pensar la formación (2012); Pablo Martins - Las Ciencias de la Educación en Uruguay (2011); País? Roberto da Silva, Rogério Adolfo de Moura e João Clemente de Souza Neto, Áreas Prioritárias para Atuação da Pedagogia Social no Brasil (2009); Na Argentina com Marcelo Krichesky, Pedagogía Social en Argentina: un campo disciplinar en construcción (2011); No Chile com Eusebio Manuel Nájera Martinez, Las educaciones sociales en los albores del siglo XXI (2011); Em Cuba com Justo Luis Pereda Rodríguez e Martín González, Bases fundacionales, actualidad y perspectivas de la Pedagogía Social cubana (2011); No Equador com Roberth Olmedo Zambrano Santos, Los antecedentes de la Pedagogía Socil en Ecuador: su preservación (2011); País? Rogério Adolfo de Moura, Pedagogia Social: o conceito, o legado alemão e os desafios para sua reconstrução na América Latina do século XXI (2011); País Danilo Streck, Ligações esquecidas: requisitos para uma Pedagogia Social Latino-Americana (2012). 
Este último texto de Streck (2012) faz referência justamente à possibilidade de a Pedagogia Social assumir o papel que se almeja também com as reflexões realizadas anteriormente, no sentido de que esta área possa promover a estruturação de uma concepção pedagógica própria latino-americana. O autor cita Paulo Freire a respeito do que ele fala da necessidade da unidade na diversidade e que a Pedagogia Social possui esse perfil de adentrar nos diversos espaços sociais e operar as transformações de dentro desses contextos.

Streck (2012, p. 37) descreve os possíveis elementos a partir da Educação Popular para construção de um projeto próprio para a Pedagogia Social: o primeiro é relativo à "Prática social como ponto de partida para a tarefa educativa"; o segundo "A leitura estrutural da sociedade, buscando identificar as relações de poder e as possibilidades de transformação"; o terceiro sobre "A crença no potencial transformador dos sujeitos que se situam à "margem" das estruturas hegemônicas"; o quarto a respeito do "Reconhecimento da pluralidade de conhecimentos, saberes, racionalidades e sentimentalidades"; e o quinto se refere "A construção de metodologias participativas, tendo o diálogo como princípio metodológico central".

Esses elementos, de acordo com o Streck (2012), incidirão em uma formação técnica e profissional que permita ao Educador Social atuar nos seguintes âmbitos: do sujeito e das relações intersubjetivas; das instituições (família, igreja, abrigos, escolas, etc.); da vinculação com movimentos e formas organizadas; do público, especialmente a implementação e construção de políticas públicas; da "massividade", onde hoje desempenham um papel importante nas mídias sociais.

\section{REFLEXÕES FINAIS}

A partir do acesso às publicações que seguem referenciadas, é possível compreender que está cada vez mais em desenvolvimento a estruturação de um campo da Educação Social - Pedagogia Social, agora no contexto latino-americano e pautado em uma perspectiva própria.

Com essa proposta de estruturação da Pedagogia Social, tendo como base os pressupostos da Educação Popular, é possível se pensar alternativas que podem ir à contramão de uma lógica imposta internacionalmente para a área da educação como um todo, e também pode ser um importante ponto de partida para renovar perspectivas de modelos existentes de Pedagogia 
Social. A esse respeito, Scocuglia (2009) defende a ideia de que a Pedagogia Social com bases teóricas freirianas pode se constituir em uma perspectiva contra-hegemônica à sociedade desigual que temos. $\mathrm{O}$ autor enfatiza dois aspectos da teoria de Paulo Freire que fundamentam essa ideia. O primeiro se refere à repercussão de sua teoria em todo o mundo, e o segundo é a tendência de conscientização crítica da realidade por parte dos sujeitos envolvidos nas práticas freirianas:

Parece-nos que o primeiro passo a considerar é a influência da Pedagogia freiriana no mundo. Sabemos que a obra de Paulo Freire é traduzida, utilizada e debatida em vários idiomas e em muitos países. Em um sentido completamente diverso da globalização hegemônica do capitalismo, podemos dizer que Freire é um dos pensadores da Educação e da Pedagogia mais globalizados. Os numerosos eventos, as publicações e as constantes referências à sua obra e ao seu legado prático-teórico demonstram a possibilidade concreta de a sua Pedagogia vir a ser um contraponto vigoroso à influência da globalização hegemônica na Educação mundial (SCOCUGLIA, 2009, p. 232).

Com os argumentos de Scocuglia, é possível justificar os empreendimentos em prol de uma nova via de pensamento educacional que busque, efetivamente, transformar realidades e não apenas produzir e reproduzir um modelo de sociedade desigual e injusto:

Por que isso ocorre? A meu ver, porque suas categorias de análise, seus principais conceitos e a força da sua prática e das práticas educativas que utilizam seu legado em todo o mundo tem oferecido denúncias, respostas e propostas convincentes aos principais problemas que as políticas educacionais enfrentam nos últimos quarenta anos, entre os quais se destacam: bilhões de analfabetos absolutos, funcionais, digitais, políticos; precária escolarização das camadas sociais subalternas; privilégio da Educação das elites; Educação bancária; reprodução dos processos opressivos nas salas de aula; necessidade de reEducação dos educadores e de oferta de condições de trabalho adequadas e quantitativas; importância das ações dialógicas na Educação; necessidade da conquista da Educação crítica pelas vias/estágios da consciência; aparato educacional voltado para os interesses, valores e necessidades das camadas oprimidas; combate aos determinismos práticose teóricos; busca da consciência da realidade nacional; a Educação e a Cultura como exercícios da liberdade; os direitos dos oprimidos ao conhecimento; o trabalho como uma das matrizes do conhecimento político; a esperança e a ousadia que combatem o fatalismo e o medo; a construção da Pedagogia 
da autonomia; as construções dos inéditos viáveis e da utopia da denúncia e do anúncio; enfim, a Educação na história como possibilidade de mudança (SCOCUGLIA, 2009, p. 232).

Essas reflexões inspiram a crença na possibilidade de que sejam tomados novos rumos em relação ao campo educacional em países de várias partes do mundo, pois os elementos necessários para realizar uma possível transformação estão dados, cabendo aos diferentes atores e instituições sociais promoverem sua efetivação. Por meio das reflexões apresentadas nessa pesquisa, já existe uma alternativa global em desenvolvimento. Basta estabelecer os caminhos possíveis para o seu reconhecimento, o que não significa uma revolução pontual do ponto de vista de imposição de um novo modelo de poder, mas sim na construção coletiva entre diferentes povos e suas culturas sabendo reconhecer as várias e múltiplas potencialidades.

As discussões pautadas nesse trabalho de pesquisa indicam assim a possibilidade de construção de um novo sentido para a Educação Social - Pedagogia Social estabelecida e construída em países europeus ao longo dos últimos cem anos.

\section{LATIN AMERICAN POPULAR EDUCATION AS A NEW DIRECTION FOR SOCIAL EDUCATION - SOCIAL PEDAGOGY}

ABSTRACT: This paper presents the analysis of part of the theoretical reflections for the theoretical background of a doctorate research that aimed to investigate the process of internationalization and consolidation of Social Pedagogy as an area of knowledge of Educational Sciences in Spain and the Social Pedagogy process of construction in Brazil. In this paper we present a theoretical reflection about the development of a pedagogical theory peculiar to Latin America. Based on the perspective of Popular Education, there exists the defense that this may suggest fundamentals and inspire new ways to structure an area that has its origins in Germany and Spain, that is, in European contexts.

KeYwords: Popular Education. Social Education. Social Pedagogy. Latin America. 


\section{LA EDUCACIÓN POPULAR LATINOAMERICANA COMO UNA NUEVA DIRECCIÓN PARA LA EDUCACIÓN SOCIAL - PEDAGOGÍA SOCIAL}

Resumen: Este trabajo presenta el análisis de una parte de las reflexiones teóricas destinadas a la fundamentación de la investigación de doctorado, que tuvo como objetivo investigar el proceso de internacionalización y consolidación de la Pedagogía Social como una área de conocimiento de las Ciencias de la Educación en España y su constitución reciente en Brasil. En este artículo se presenta una reflexión teórica sobre el desarrollo de una teoría pedagógica peculiar en América Latina. Con base en la perspectiva de la Educación Popular, existe la defensa de que esta puede sugerir fundamentos e inspirar nuevas caminos para estructurar una área que tiene sus orígenes en Alemania y, después en España, o sea, en el contexto europeo.

PalABRAs-Clave: Educación Popular. Educación Social. Pedagogía social. América Latina.

\section{NOTAS}

1) Parte desse artigo deriva da tese "O desenvolvimento da pedagogia social sob a perspectiva comparada: o estágio atual no Brasil e Espanha" (MACHADO, 2014).

2) É importante esclarecer que a Pedagogia Social surge em contraposição a uma Pedagogia Individual. É uma reflexão científica sobre os processos educativos que acontecem nas trocas culturais - sociais entre grupos humanos. A Pedagogia Social é uma disciplina científica que fundamenta epistemologicamente as análises que emergem das práticas da Educação Social. Educação Social é o campo das práticas educativas que acontecem em diferentes espaços com todos os sujeitos.

\section{REFERÊNCIAS}

CAMORS, J. A Pedagogia Social na América Latina. In: MOURA, R., NETO, J. C. S.; SILVA, R. (Org.). Pedagogia Social. São Paulo: Expressão e Arte Editora, 2009.

. Lo social: um caminho para recuperar identidades. In: SILVA, R. da. et al. (Org.). Pedagogia Social: contribuições para uma Teoria Geral da Educação Social. São Paulo: Expressão e Arte Editora, 2011.

. El Educador Social en Uruguay: aspectos históricos y fundamentos teóricos que explican la construcción de la figura profesional. Montevideo: Grupo Magro, 2012.

DEZIN, N. K. The research act. 3. ed. Englewood Cliffi. NJ: Prentice Hall, 1989.

FIELDING, N.; SCHREIER, M. Introduction: On the Compatibility between Qualitative and Quantitative Research Methods. In: Forum Qualitative Sozialforschung. v. 2, 2001. 
FLICK, U. Introdução à Pesquisa Qualitativa. 3.ed. Porto Alegre: Artmed, 2009.

GADOTTI, M. Educação Popular, Educação Social, Educação Comunitária: conceitos e práticas diversas, cimentadas por uma causa comum. Revista Diálogos, v. 18, 2012.

HÄMÄLÄINEM, J. The concept of Social Pedagogy in the Field of Social Work. Journal of Social Work. London: Sage Publications, p. 69-80, 2003.

KRICHESKY, M. Pedagogía Social en Argentina: un campo disciplinar en construcción. In: SILVA, Roberto da. et al. (Org.). Pedagogia Social: contribuições para uma Teoria Geral da Educação Social. São Paulo: Expressão e Arte Editora, 2011.

LOURENÇO FILHO, M. B. Educação Comparada. São Paulo: Melhoramentos, 1961.

MACHADO, É. R. A constituição da Pedagogia Social no contexto educacional brasileiro. 2010. Dissertação (Mestrado em Educação) - Universidade Federal de Santa Catarina. Programa de Pós-Graduação em Educação. Florianópolis, 2010.

O desenvolvimento da pedagogia social sob a perspectiva comparada: o estágio atual no Brasil e Espanha. 2014. 296 f. Tese (Doutorado em Educação) - Programa de Pós-Graduação em Educação, Universidade de São Paulo (USP), São Paulo, 2014.

. Interfaces between Popular Education of Paulo Freire and Social Pedagogy In: Binational Conference. Siegen/Germany. Internationale Perspektiven derSubjektentwicklungs und Inklusionsforschung. Siegen: Uni Print der Universität Siegen, 2011. p. 307-320.

. As relações entre a Pedagogia Social e a Educação Popular no Brasil. Revista Diálogos, v. 18, 2012.

MARTINEZ, E. M. N. M. Las educaciones sociales en los albores del siglo XXI. In: SILVA, R. da. et al. (Org.). Pedagogia Social: contribuições para uma Teoria Geral da Educação Social. São Paulo: Expressão e Arte Editora, 2011.

MARTINS, P. Las Ciencias de la Educación en Uruguay. Archivos de Ciencias de la Educación, v. 5, p. 37-48, 2011.

MOLLENHAUER, K. Die Ursprünge der Sozialpädagogik in der industriellen Gesellschaft. Weinheim: Julius Beltz, 1959.

MORALES, M.; ESPIGA, H.; LÓPEZ, W. Educación Social en Uruguay: apuntes para pensar la formación. Revista Pedagogíca, n. 2, abr. 2012.

MOURA, R. Pedagogia Social: o conceito, o legado alemão e os desafios para sua reconstrução na América Latina do século XXI. In: SILVA, R. da. et al. (Org.). Pedagogia Social: contribuições para uma Teoria Geral da Educação Social. São Paulo: Expressão e Arte Editora, 2011.

$\therefore$ SOUZA NETO, J. C. de; SILVA, R. da (Org.). Pedagogia Social. São Paulo: Expressão e Arte Editora, 2009. 
(Org.). Pedagogia Social. 2. ed. São Paulo: Expressão e Arte Editora, 2011.

NATORP. P. Pedagogía Social: teoría de la educación de la voluntad. Madri: La Lectura, 1913.

NOHL, H. Die pädagogische Bewegung in Deutschland und ihre Theorie. Zweite, durchgesehene und mit einem Nachwort versehene Auflage. Frankfurt am Main: Gerhard Schulte-Bulmke. 1935.

PAIVA, J. S. Pedagogia social, educação popular, as redes que se tecem em outro espaço educacional possível. 2009. Disponível em: <http://www.psicopedagogia.com.br/>. Acesso em: 21 set. 2016.

RODRIGUEZ, J. L. P.; GONZÁLEZ, M. G. Bases fundacionales, actualidad y perspectivas de la Pedagogía Social cubana. In: SILVA, R. da et al. (Org.). Pedagogia Social: contribuições para uma Teoria Geral da Educação Social. São Paulo: Expressão e Arte Editora, 2011.

ROUQUIÉ, A. O extremo ocidente: introdução à América Latina. São Paulo: EDUSP, 1991. RYYNÄNEM, S. A pedagogia social na Finlândia e o contexto brasileiro. In: MOURA, R.; NETO, J. C. S.; SILVA, R. (Org.). Pedagogia Social. São Paulo: Expressão e Arte Editora, 2009. p. 61-82.

SOUZA SANTOS, B.; MENEZES, M. P. (Org.). Epistemologias do Sul. São Paulo: Cortez, 2010.

SCHRIEWER, J. Sistema Mundial e Inter-Relacionamento de Redes: a Internacionalização da Educação e o Papel da Pesquisa Comparativa. Revista brasileira de Estudos Pedagógicos, v. 76, p. 241-304, 1995.

SCHUGURENSKY, D.; SILVER, M. Social Pedagogy: Historical traditions and transnational connections. Education Policy Analysis Archives, v. 21, n. 35, p. 1-20, 2013.

SCOCUGLIA, A. C. A pedagogia social de Paulo Freire como contraponto da Pedagogia Globalizada. In: MOURA, R.; NETO, J. C. S.; SILVA, R. (Org.). Pedagogia Social. São Paulo: Expressão e Arte Editora, 2009. p. 225-240.

STRECK, D. R. Encobrimentos e Emergências Pedagógicas na América Latina. Revista Lusófona de Educação, n. 6, p. 55- 66, 2005.

. Ligações esquecidas: requisitos para uma pedagogia social latino-americana. Revista Diálogos, v. 18, 2012.

.; ADAMS, T.; MORETTI, C. Z. Pensamento pedagógico em nossa América: uma introdução. In: STRECK, Danilo R. (Org.). Fontes da Pedagogia Latino-Americana: uma antologia. Belo Horizonte: Autêntica, 2010

; SANTOS, K. Educação de Jovens e Adultos: diálogos com a Pedagogia Social e Educação Popular. Eccos Revista Científica, n. 25, jan./jun. 2011. 
ZAMBRANO SANTOS, R. O. Los antecedentes de la Pedagogía Social en Ecuador: su preservación. In: SILVA, Roberto da. et al. (Org.). Pedagogia Social: contribuições para uma Teoria Geral da Educação Social. São Paulo: Expressão e Arte Editora, 2011.

ÉRICO RIBAS MACHADO: Professor Adjunto no Departamento de Educação da Universidade Estadual de Ponta Grossa. Doutor em Educação pela Universidade de São Paulo. Mestre em Educação pela Universidade Federal de Santa Catarina. Líder do Núcleo de Estudos, Pesquisas e Extensão em Pedagogia, Pedagogia Social e Educação Social (NUPEPES).

E-mail: ericormachado@gmail.com 